\title{
The Epidemiology of Deafness
}

\author{
Abraham M. Sheffield ${ }^{1}$ and Richard J.H. Smith $2,3,4,5$ \\ ${ }^{1}$ Department of Otolaryngology, Head and Neck Surgery, University of lowa, lowa City, lowa 52242 \\ ${ }^{2}$ Molecular Otolaryngology and Renal Research Laboratories (MORL), Department of Otolaryngology, \\ University of lowa, lowa City, lowa 52242 \\ ${ }^{3}$ Department of Molecular Physiology \& Biophysics, University of lowa, lowa City, lowa 52242 \\ ${ }^{4}$ Department of Pediatrics, University of lowa, lowa City, lowa 52242 \\ ${ }^{5}$ Department of Internal Medicine, University of lowa, lowa City, lowa 52242 \\ Correspondence: richard-smith@uiowa.edu
}

Hearing loss is the most common sensory deficit worldwide. It affects $\sim 5 \%$ of the world population, impacts people of all ages, and exacts a significant personal and societal cost. This review presents epidemiological data on hearing loss. We discuss hereditary hearing loss, complex hearing loss with genetic and environmental factors, and hearing loss that is more clearly related to environment. We also discuss the disparity in hearing loss across the world, with more economically developed countries having overall lower rates of hearing loss compared with developing countries, and the opportunity to improve diagnosis, prevention, and treatment of this disorder.

$\mathrm{H}$ earing loss is the most common sensory deficit worldwide, affecting more than half a billion people (Smith et al. 2005; Wilson et al. 2017). Normal hearing is defined as having hearing thresholds of $\leq 25 \mathrm{~dB}$ in both ears. The World Health Organization (WHO) defines hearing loss as a speech-frequency pure tone average $>25 \mathrm{~dB}$ at $0.5,1,2$, and $4 \mathrm{kHz}$ in the better hearing ear (Yamasoba et al. 2013). Disabling hearing loss is defined as hearing loss $>40 \mathrm{~dB}$ in the better hearing ear in adults and $>30 \mathrm{~dB}$ in the better hearing ear in children (see who.int/newsroom/fact-sheets/detail/deafness-and-hearingloss). Degrees of hearing loss are classified as mild ( $26 \mathrm{~dB}$ to $40 \mathrm{~dB}$ ), moderate $(41 \mathrm{~dB}$ to $55 \mathrm{~dB})$, moderately severe ( $56 \mathrm{~dB}$ to $70 \mathrm{~dB}$ ), severe $(71 \mathrm{~dB}$ to $90 \mathrm{~dB})$, or profound $(\geq 91 \mathrm{~dB})$ (Koffler et al. 2015).

Although there is no clear demarcation, the term "hard of hearing" is sometimes used to refer to people with mild-to-moderate (and sometimes severe) hearing loss, whereas the term "deaf" (lower case "d") is more commonly reserved for those with severe or profound hearing loss (Smith et al. 2005; also see who.int/newsroom/fact-sheets/detail/deafness-and-hearingloss). The term "Deafness" (upper case “D”) describes a cultural group united by the use of sign language for communication. People with any degree of hearing loss are sometimes described as "hearing impaired." Although this term is intended to be neutral, it may arouse negative feelings in some, especially among those in the Deaf community who do not view hearing loss as an impairment (Smith et al. 2005).

Because of the great heterogeneity that exists, there are many ways to describe and categorize hearing loss. These include etiology, age of onset, time of onset in relation to language develop-

Editors: Guy P. Richardson and Christine Petit

Additional Perspectives on Function and Dysfunction of the Cochlea available at www.perspectivesinmedicine.org

Copyright (C) 2019 Cold Spring Harbor Laboratory Press; all rights reserved; doi: 10.1101/cshperspect.a033258

Cite this article as Cold Spring Harb Perspect Med 2019;9:a033258 
A.M. Sheffield and R.J.H. Smith

ment, clinical presentation, severity, frequency loss, number of ears affected, and anatomic defect. In terms of anatomic defects, there are two broad categories: conductive hearing loss (CHL) and sensorineural hearing loss (SNHL). Mixed hearing loss is a third type that is used to describe cases in which both CHL and SNHL are present in the same ear. Etiologically based classification of hearing loss can be broadly divided into genetic versus nongenetic. It is important to note that genetic hearing loss is not synonymous with congenital hearing loss. Congenital hearing loss simply refers to hearing loss that is present since birth regardless of etiology. Genetic hearing loss refers to a genetically inherited etiology, which may be present at birth (i.e., congenital) or develop at any time thereafter (Shibata et al. 2015).

This review will discuss the epidemiology of hearing loss. We will address genetic, as well as environmental causes of hearing loss. Hearing loss of genetic etiology can be subcategorized into simple Mendelian inheritance versus complex inheritance. Mendelian inherited hearing loss is subdivided into syndromic or nonsyndromic, based on the presence or absence of coinherited anomalies. Syndromic and nonsyndromic conditions are further subdivided by inheritance pattern: autosomal dominant, autosomal recessive, $\mathrm{X}$-linked, and mitochondrial (Shibata et al. 2015). Complex inheritance, in which there are significant contributions from both genetic and environmental factors, will also be discussed. We will conclude with addressing environmental factors.

There is significant disparity in rates of hearing loss between developed nations and developing nations (see Fig. 1). It should be noted that data on the incidence and causes of hearing loss are most readily available from developed nations in which there are newborn hearing screening programs. The information is not as well documented for most developing countries. We attempt to include appropriate international data where possible, but many of the epidemiological studies come out of the United States and Europe.

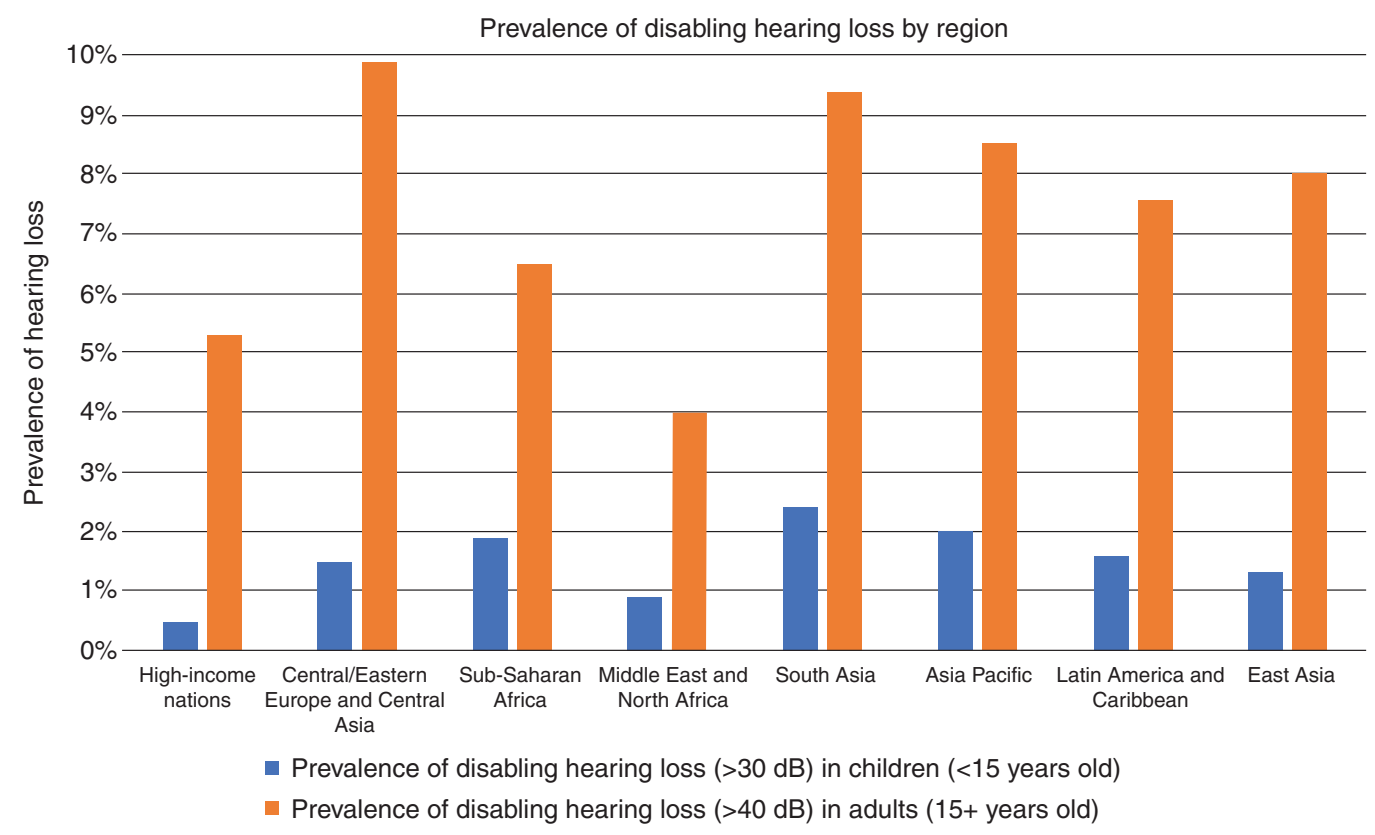

Figure 1. Prevalence of disabling hearing loss in adults (15 years and older) and children (younger than 15 years). Disabling hearing loss is defined by the World Health Organization (WHO) as thresholds $>30 \mathrm{~dB}$ for children and $>40 \mathrm{~dB}$ for adults. (Data based on 2018 WHO Global Estimates on Prevalence of Hearing Loss.) 
The Epidemiology of Deafness

\section{NONSYNDROMIC GENETIC HEARING LOSS OVERVIEW}

Approximately half of hearing loss cases have a genetic etiology (see Fig. 2). Genetic hearing loss accounts for at least $50 \%-60 \%$ of childhood hearing loss cases in developed countries (Koffler et al. 2015). A simple Mendelian inheritance pattern is common for genetic hearing loss. Nonsyndromic describes hearing loss of genetic etiology with no other phenotypic manifestations. Nonsyndromic SNHL accounts for $\sim 70 \%$ of congenital genetic hearing loss. The most common inheritance pattern of congenital nonsyndromic SNHL is autosomal recessive ( $75 \%-$ $80 \%)$. Autosomal dominant SNHL represents $\sim 20 \%$, X-linked $<2 \%$, and mitochondrial $<1 \%$ (Shibata et al. 2015). Nonsyndromic genetic loci for hearing loss are named with the convention of DFNB\# (autosomal recessive), DFNA\# (autosomal dominant), and DFNX\# (X-linked). To date, there are 157 genetic loci with 110 identified genes (see hereditaryhearingloss.org).

\section{Autosomal Recessive Nonsyndromic Hearing Loss}

Autosomal recessive nonsyndromic hearing loss (ARNSHL) is the most common type of genetic hearing loss. It is most often characterized by prelingual onset (before speech development) and is usually severe-to-profound across all frequencies. According to the Hereditary Hearing Loss Homepage, mutations in 68 genes have been identified as causally related to ARNSHL (see hereditaryhearingloss.org). The first causative locus was mapped in 1994 (Guilford et al. 1994). Three years later, the gene at this locus was identified as GJB2 (Kelsell et al. 1997). GJB2 encodes connexin 26 , a protein that oligomerizes to form a connexon. Connexons in adjacent cells dock to form a gap junction, which are critical in the inner ear for recycling potassium and other ions to maintain cochlear homeostasis (Mammano 2018). Mutations in GJB2 are the most common cause of severe-to-profound ARNSHL, accounting for up to $50 \%$ of people with this degree of congenital hearing loss in many world populations. There is great allelic heterogeneity, with $>100$ different deafnesscausing mutations identified in this single gene. Notably, different mutations in GJB2 predominate in different populations. For example, the 35delG mutation is most common in Europeans and European-Americans and has a carrier frequency of $\sim 2.5 \%$ in the Midwestern United States. In comparison, the $167 \mathrm{delT}$ mutation has a carrier frequency of $\sim 4 \%$ in the Ashkenazi Jewish population and the $235 \mathrm{delC}$ mutation is the most common GJB2 mutation in the Japanese (Shibata et al. 2015).

In a recent study using comprehensive genetic testing by means of targeted genomic enrichment and massively parallel sequencing (TGE+MPS) to identify the genetic etiology of hearing loss in 1119 patients with nonsyndromic hearing loss, although 49 different genes

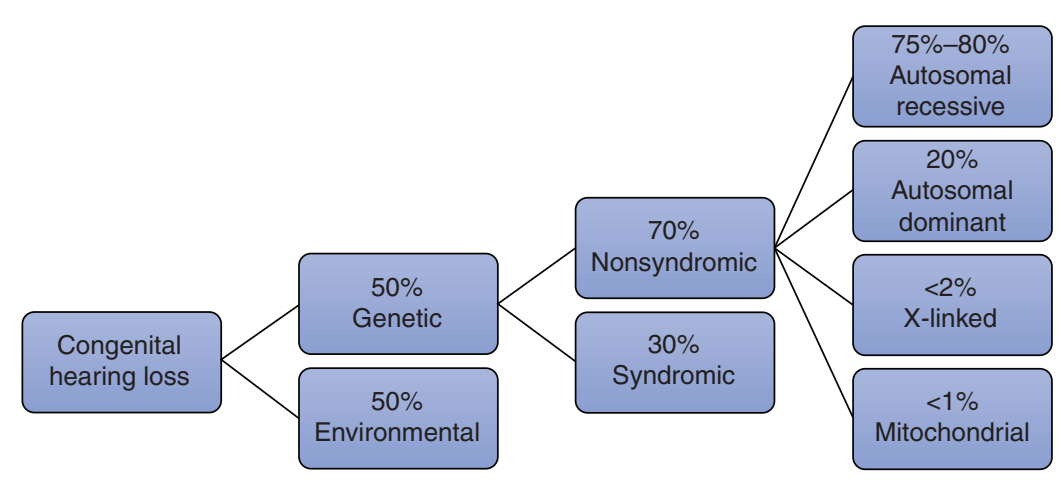

Figure 2. General global overview of environmental and genetic contributions to congenital hearing loss; percentages change in specific countries and under specific conditions (see Smith et al. 2005). Environmental etiologies include infections, ototoxic medications, prematurity, and others. 
A.M. Sheffield and R.J.H. Smith

were implicated in hearing loss, nearly threefourths of the diagnoses were attributable to 10 genes with mutations in GJB2 being most common at $22 \%$. The three next most frequently implicated genes were STRC (16\%), SLC26A4 (7\%), and TECTA (5\%). Of note, the frequency of causative genes varied both by degree of hearing loss and by ethnicity. For example, although GJB2 was the most common cause of severe-toprofound hearing loss $(20 \%)$, in patients with mild-to-moderate hearing loss, mutations in STRC are the most likely etiology (30\%). In Caucasians and Hispanics, STRC-related hearing loss was as common as GJB2-related hearing loss, but GJB2 mutations were much more common than STRC mutations in Middle Eastern and Asian patients. GJB2-related hearing loss was not identified in any African-American patients (Sloan-Heggen et al. 2016).

\section{Autosomal Dominant Nonsyndromic Hearing Loss}

Autosomal dominant nonsyndromic SNHL represents $\sim 20 \%$ of nonsyndromic hearing loss. In contrast to autosomal recessive, dominant forms tend to be characterized by hearing loss with postlingual onset, a progressive course, and often a milder degree of hearing loss than recessive forms (Shibata et al. 2015). According to the Hereditary Hearing Loss Homepage, mutations in 37 genes have been identified that cause autosomal dominant nonsyndromic hearing loss (ADNSHL) (see hereditaryhearingloss. org). Several forms of ADNSHL have characteristic audio profiles. For example, one of the most common causes of ADNSHL is mutations in the gene $K C N Q 4$, which encodes a potassium channel protein. Patients with mutations in this gene have a high frequency of hearing loss. In contrast, mutations in the Wolfram syndrome 1 gene (WFS1) cause a very characteristic low-frequency hearing loss $(<2 \mathrm{kHz})$ (Chang 2015).

\section{X-Linked Nonsyndromic Hearing Loss}

$\mathrm{X}$-linked nonsyndromic hearing loss accounts for $<2 \%$ of nonsyndromic hearing loss. According to the Hereditary Hearing Loss Homepage, five causative genes have been identified (see hereditaryhearingloss.org). Mutations in a transcription factor gene, POU 3F4, are the most common cause of X-linked nonsyndromic hearing loss. Mutations in this gene cause congenital stapes fixation with cochlear hypoplasia and widening of the lateral internal auditory canal. Hearing loss is usually mixed and stapes surgery risks a perilymph gusher (Chang 2015; Shibata et al. 2015).

\section{SYNDROMIC GENETIC HEARING LOSS OVERVIEW}

Syndromic SNHL accounts for $~ 30 \%$ of congenital genetic hearing loss and describes forms of hearing loss that are accompanied by additional clinical phenotypes, most frequently involving the eye, kidney, and/or skin, although the musculoskeletal and nervous systems are also frequently involved in syndromic hearing loss. There are $>700$ syndromes that include hearing loss, although in aggregate, syndromic forms of SNHL are less common than nonsyndromic forms. Some of the most common syndromic forms of hearing loss include Usher syndrome, Waardenburg syndrome (WS), Pendred syndrome, Jervell and Lange-Nielsen syndrome (JLNS), Alport syndrome, branchio-oto-renal (BOR) syndrome, Stickler syndrome, Treacher Collins syndrome, and CHARGE syndrome (see Table 1) (Korver et al. 2017).

Some syndromic forms of hearing loss initially present with only hearing loss as the syndromic manifestations appear later. These types of syndromic hearing loss are called nonsyndromic hearing loss mimics. For example, type 1 Usher syndrome presents as congenital profound hearing loss, and the associated progressive vision loss typically does not begin until late childhood. A study by Sloan-Heggen et al. (2016) suggests that comprehensive clinical genetic testing of patients with hearing loss is important for identifying these nonsyndromic mimics. These investigators identified nonsyndromic mimics in $9 \%$ of patients tested. Diagnoses included Usher syndrome, Pendred syndrome, Deafness-infertility syndrome, Alström syndrome, autosomal dominant nonocular 
The Epidemiology of Deafness

Table 1. Overview of common forms of syndromic hearing loss

\begin{tabular}{|c|c|c|}
\hline Syndrome & Proteins involved (coding genes) & $\begin{array}{c}\text { Clinical characteristics (in addition to } \\
\text { hearing loss) }\end{array}$ \\
\hline Alport & $\begin{array}{l}\text { Collagen } \alpha 3 \text { (IV) chain (COL4A3), collagen } \alpha 4 \text { (IV) } \\
\text { chain }(C O L 4 A 4), \text { and collagen } \alpha 5 \text { (IV) chain } \\
(C O L 4 A 5)\end{array}$ & $\begin{array}{l}\text { Glomerular kidney disease } \\
\text { Eye abnormalities }\end{array}$ \\
\hline $\begin{array}{l}\text { Branchio-oto- } \\
\quad \text { renal }\end{array}$ & $\begin{array}{l}\text { Eyes absent homolog } 1 \text { (EYA1), homeobox protein } \\
\text { SIX1 (SIX1), and homeobox protein SIX5 (SIX5) }\end{array}$ & $\begin{array}{l}\text { Branchial cysts or fistulae } \\
\text { External and middle ear anomalies } \\
\text { Renal abnormalities }\end{array}$ \\
\hline CHARGE & $\begin{array}{l}\text { Semaphorin 3E (SEMA3E) and Chromodomain } \\
\text { helicase DNA-binding protein } 7(C H D 7)\end{array}$ & $\begin{array}{l}\text { Coloboma of the eye } \\
\text { Heart defects } \\
\text { Choanal atresia } \\
\text { Retardation of growth and development } \\
\text { Ear abnormalities (external, middle, and } \\
\quad \text { inner) }\end{array}$ \\
\hline $\begin{array}{l}\text { Jervell and Lange- } \\
\text { Nielsen }\end{array}$ & $\begin{array}{l}\text { Potassium voltage-gated channel subfamily E member } \\
1 \text { (KCNE1), and potassium voltage-gated channel } \\
\text { subfamily KQT member } 1 \text { (KCNQ1) }\end{array}$ & Cardiac arrhythmia (long QT interval) \\
\hline Pendred & Pendrin (SLC26A4) & $\begin{array}{l}\text { Enlarged vestibular aqueduct } \\
\text { Thyroid goiter }\end{array}$ \\
\hline Stickler & $\begin{array}{l}\text { Collagen } \alpha 1 \text { (II) chain (COL2A1), collagen } \alpha 1 \text { (IX) } \\
\text { chain }(C O L 9 A 1) \text {, collagen } \alpha 2 \text { (IX) chain (COL9A2), } \\
\text { collagen } \alpha 1 \text { (XI) chain }(C O L 11 A 1) \text {, and collagen } \alpha 2 \\
\text { (XI) chain }(C O L 11 A 2)\end{array}$ & $\begin{array}{l}\text { Skeletal and joint abnormalities } \\
\text { Myopia } \\
\text { Vitreoretinal degeneration }\end{array}$ \\
\hline Treacher Collins & $\begin{array}{l}\text { Treacle protein (TCOF1), DNA-directed RNA } \\
\text { polymerases I and III subunit RPAC2 (POLR1C), } \\
\text { and DNA-directed RNA polymerases I and III } \\
\text { subunit RPAC2 (POLR1D) }\end{array}$ & $\begin{array}{l}\text { Characteristic facies (secondary to } \\
\text { micrognathia, malar and zygomatic } \\
\text { hypoplasia) } \\
\text { Cleft palate } \\
\text { Eyelid coloboma } \\
\text { External and middle ear anomalies }\end{array}$ \\
\hline Usher & $\begin{array}{l}\text { Type 1: Unconventional myosin VIIa (MYO7A), } \\
\text { harmonin (USH1C), cadherin } 23(C D H 23), \\
\text { protocadherin } 15(P C D H 15) \text {, Usher syndrome type } \\
1 \text { G protein }(U S H 1 G) \text {, and calcium and integrin- } \\
\text { binding family member } 2 \text { (CIB2) } \\
\text { Type 2: Usherin (USH2A), adhesion G protein- } \\
\text { coupled receptor V1 (ADGRV1), and whirlin } \\
\text { (WHRN) } \\
\text { Type 3: Clarin } 1(C L R N 1)\end{array}$ & $\begin{array}{l}\text { Retinitis pigmentosa } \\
\text { Vestibular dysfunction (types } 1 \text { and } 3 \text { ) }\end{array}$ \\
\hline Waardenburg & $\begin{array}{l}\text { Paired box protein Pax3 (PAX3), microphthalmia- } \\
\text { associated transcription factor }(M I T F) \text {, endothelin } \\
3(E D N 3) \text {, endothelin B receptor }(E D N R B) \text {, zinc- } \\
\text { finger protein SNAI2 (SNAI2), and transcription } \\
\text { factor SOX10 (SOX10) }\end{array}$ & $\begin{array}{l}\text { Pigmentary abnormalities of skin, hair, } \\
\text { and iris }\end{array}$ \\
\hline
\end{tabular}

Data adapted from Korver et al. (2017) and Hereditary Hearing Loss Homepage (see hereditaryhearingloss.org).

Stickler syndrome, BOR syndrome, MYH9-associated disease, and Wolfram syndrome (SloanHeggen et al. 2016).

Several genes are implicated in both syndromic and nonsyndromic forms are SNHL.
For example, mutations in SLC26A4 the gene are responsible for Pendred syndrome and also ARNSHL at the DFNB4 locus. GJB2 provides another example of this phenotypic heterogeneity. Although most mutations in GJB2 are 
A.M. Sheffield and R.J.H. Smith

implicated in nonsyndromic SNHL, some mutations in this gene cause various autosomal dominant syndromes that combine hearing loss and skin involvement (see hereditaryhearingloss .org).

\section{Autosomal Recessive Syndromic Hearing Loss}

\section{Pendred Syndrome}

Pendred syndrome is the most common form of syndromic SNHL. Its prevalence is estimated at $\sim 7.5$ per 100,000 individuals and it may account for up to $8 \%$ of hereditary deafness. Most cases are secondary to mutations in SLC26A4, which encodes the iodide-chloride symporter known as pendrin (Shibata et al. 2015). Pendrin is expressed in the inner ear, kidneys, and thyroid. The hearing loss is usually prelingual, bilateral, and profound, although it can be later onset and progressive (Koffler et al. 2015). Temporal bone findings include bilateral enlarged vestibular aqueducts and cochlear hypoplasia; affected individuals also often develop euthyroid goiter in their second decade (Shibata et al. 2015).

\section{Usher Syndrome}

Approximately 40 syndromes cause both hearing loss and blindness, with Usher syndrome being responsible for approximately half of cases; its ocular manifestation is retinitis pigmentosa. The prevalence of Usher syndrome is $1: 6000$ to $1: 10,000$ in the United States. Subclassified into three variants-USH1, USH2, and USH3 - patients with USH1 have severeto-profound congenital bilateral SNHL and congenital vestibular dysfunction; retinitis pigmentosa develops during childhood. Patients with USH2 have moderate-to-severe congenital SNHL, no vestibular dysfunction and retinitis pigmentosa that manifests in the third to fourth decade of life. Patient with USH3 have progressive hearing loss, which begins before the third decade, variable vestibular dysfunction and variable onset of retinitis pigmentosa (Shibata et al. 2015).

\section{Jervell and Lange-Nielsen Syndrome}

JLNS is an autosomal recessively inherited syndrome characterized by congenital hearing loss, prolonged QT interval and syncopal attacks. Mutations in two potassium channel genes, KCNQ1 and KCNE1, cause JLNS. These potassium channels are expressed in the inner ear and the heart. Although this syndrome is rare ( $~ 0.20 \%$ of congenital hearing loss), it is important to diagnose because of the potential for fatal cardiac arrhythmias (Shibata et al. 2015; Korver et al. 2017).

\section{Autosomal Dominant Syndromic Hearing Loss}

\section{Waardenburg Syndrome}

WS has an incidence of one to two per 20,000 people and represents $\sim 1 \%-3 \%$ of all congenital hearing loss cases (Koffler et al. 2015). In addition to SNHL, syndromic manifestations include pigmentary abnormalities of the hair, iris, and skin (e.g., white forelock, heterochromia iridis) and dystopia canthorum (lateral displacement of the inner canthi of the eyes). The syndrome is divided into four subtypes. Type I, caused by mutations in $P A X 3$, has all of the above features. Persons with WS type II do not have dystopia canthorum. Type III, also known as Klein-Waardenburg syndrome, has the features of type I as well as hypoplasia or contracture of the upper extremities and is also caused by mutations in PAX3. Type IV, also known as Waardenburg-Shah syndrome, is associated with Hirschsprung disease. Unlike the autosomal dominant inheritance patter of the first three types, type IV is inherited in an autosomal recessive pattern (Shibata et al. 2015).

\section{Stickler Syndrome}

Stickler syndrome is caused by mutations in collagen proteins and is characterized by ocular, skeletal, orofacial, and auditory abnormalities. It can be either autosomal dominant or recessive inheritance (Koffler et al. 2015) and has an estimated incidence of one in 7500 to 10,000 newborns. There are five subtypes based 
The Epidemiology of Deafness

on the affected collagen gene-types 1,2 , and 3 (COL2A1, COL11A1, COL11A2) are autosomal dominant; types 4 and 5 (COL9A1, COL9A2) are autosomal recessive. There is a significant phenotypic heterogeneity among patients and the hearing loss may be sensorineural, conductive, or mixed. Stickler syndrome is the most common syndrome associated with Pierre Robin Sequence and CHL, if present, is typically caused by otitis media secondary to cleft-palate-associated Eustachian tube dysfunction. The incidence of SNHL increases with age in patients with Stickler syndrome and its pathogenesis is not completely understood (Shibata et al. 2015).

\section{Branchio-Oto-Renal Syndrome}

BOR syndrome has a prevalence of $\sim 1$ in 40,000 newborns and affects $2 \%$ of profoundly deaf children. It is autosomal dominant with $\sim 100 \%$ penetrance. Ninety percent of persons with BOR have hearing loss, which is sensorineural $(20 \%)$, conductive $(30 \%)$, or mixed (50\%). One-third of persons have severe hearing loss and, in one-quarter of persons, the hearing loss is progressive. The external, middle, and inner ear may all be involved. Otologic phenotypes include preauricular pits or tags, auricular malformations including microtia and external auditory canal stenosis, ossicular malformation, facial nerve dehiscence, absence of oval window, cochlear hypoplasia, enlarged vestibular aqueducts, and hypoplasia of the lateral semicircular canal. Other clinical findings include branchial cleft fistulae, sinuses or cysts, and renal anomalies (Shibata et al. 2015). Mutations in EYA1 gene are the most common cause of BOR syndrome ( $\sim 40 \%$ of cases), although mutations in SIX1 and SIX5 genes have also been implicated in this disease phenotype (Koffler et al. 2015).

\section{Treacher Collins Syndrome}

Treacher Collins syndrome is characterized by abnormalities of craniofacial development. The incidence is $\sim 1$ in 50,000 people, with the vast majority of cases inherited in an autosomal dominant fashion ( $\sim 1 \%$ are inherited recessive- ly). Half of persons with Treacher Collins syndrome have CHL secondary to ossicular chain defects (Koffler et al. 2015).

\section{X-Linked Syndromic Hearing Loss}

\section{Alport Syndrome}

Alport syndrome has a prevalence of $\sim 1$ in 5000 in the United States. It is a disease that affects the inner ear, eye, and kidneys. It is caused by mutations in type IV collagen, which is a major structural component of basement membranes in these organs. The hearing loss is a progressive high-frequency SNHL. The majority of mutations $(\sim 80 \%)$ are found in COL4A5, an X chromosome gene. Mutations in two autosomal genes, COL4A3 and COL4A4, cause autosomal dominant and autosomal recessive Alport syndrome (Shibata et al. 2015).

\section{Mitochondrial Inheritance}

Mitochondrial disorders are inherited maternally rather than in a classic Mendelian pattern. These disorders affect tissues with high energy demands, including the cochlea. Examples include MELAS (mitochondrial encephalopathy, lactic acidosis, and stroke-like episodes) syndrome, MERRF (myoclonic epilepsy with red ragged fibers) syndrome, Kearns-Sayre syndrome, and MIDD (maternally inherited diabetes and deafness) (Chang 2015). MIDD affects an estimated $0.5 \%$ to $2.8 \%$ of patients with type 2 diabetes mellitus (Guillausseau et al. 2001). Hearing loss of mitochondrial inheritance tends to have a broad onset, ranging in age from 5 to 50 years. The degree of hearing loss is variable but nevertheless tends to be progressive (Shibata et al. 2015).

\section{COMPLEX INHERITANCE OVERVIEW}

Some forms of hearing loss have more complex etiology and involve the interplay between genetic factors and environmental exposures. Discussion of mitochondrial disease-related hearing loss provides a natural transition to a discussion of hearing loss that is significantly 
A.M. Sheffield and R.J.H. Smith

influenced by both genetic and environmental factors. We will discuss aminoglycoside-induced hearing loss, age-related hearing loss, and otosclerosis.

\section{Aminoglycoside-Induced Hearing Loss}

Treatment with aminoglycoside antibiotics has the known risk of SNHL. The use of ototoxic medications is thought to be responsible for a large proportion of hearing loss in China. Neomycin and kanamycin were routinely administered in high doses during the cultural revolution in China in the 1960s and 1970s (Tucci et al. 2010). Several variants in the mitochondrial $12 \mathrm{~S}$ ribosomal RNA (rRNA) gene, MT-RNR1, are associated with increased susceptibility to aminoglycoside-induced ototoxicity. These variants (A1555G, C1494T, T1095C, 961delT+C(n)) make the structure of human $12 \mathrm{~S}$ rRNA more similar to bacterial rRNA, the target of aminoglycosides (Ealy et al. 2011). The prevalence of hearing loss following treatment with aminoglycosides is estimated to range from $2 \%$ to $25 \%$ (O'Sullivan et al. 2017). Notably, the hearing loss may appear months after aminoglycoside exposure (Shibata et al. 2015).

Nearly $100 \%$ of patients with the A1555G mutation in $M T-R N R 1$ are reported to develop hearing loss following aminoglycoside exposure, even after a single dose (Usami et al. 1998). Given the known side effects, many developed countries regulate the use of aminoglycosides; however, these antibiotics are often used as first-line therapy in some developing countries because of their low cost and low incidence of antibiotic resistance (O'Sullivan et al. 2017). Aminoglycosides are also frequently used in neonatal intensive care units (NICUs) as initial empiric therapy for neonatal sepsis. A 2005 survey showed that $22 \%$ of NICU patients in the United States are treated with gentamicin (Grohskopf et al. 2005). The rate of aminoglycoside administration in some NICUs is much higher, even approaching 100\% (Ealy et al. 2011). A 2011 study tested for these MT-RNR1 variants in NICU patients at the University of Iowa and found a prevalence of $1.85 \%$, which is not significantly different from the prevalence in the general population. The most common mutations identified in this NICU population were A827G and 961delT+C(n), each with a frequency of $0.78 \%$. With $1 \%-2 \%$ of the population at risk for hearing loss if treated with aminoglycosides, there are efforts to identify those who are at highest risk so that alternative treatments can be used if possible (Ealy et al. 2011).

\section{Presbycusis}

Age-related hearing loss or presbycusis is one of the most common chronic conditions and the most common sensory deficit affecting aging adults (Bowl and Dawson 2018). Hearing ability decreases with age. This process begins physiologically in the third decade and it is most often the high-frequency hearing that first becomes impaired. The etiology of presbycusis is complex and multifactorial. Risk factors can be divided into four categories: cochlear aging (individual age), environment (e.g., noise exposure, ototoxic medications), genetic predisposition (e.g., sex, ethnicity, genetic variants), and medical comorbidities (e.g., hypertension, diabetes, stroke, tobacco use) (Yamasoba et al. 2013).

A number of studies have been published reporting audiometric data from large cohorts, including the Framingham Study (Gates et al. 1990), Baltimore Longitudinal Study of Aging (Brant and Fozard 1990), Epidemiology of Hearing Loss Study in Beaver Dam (Cruickshanks et al. 1998), Health ABC Study (Helzner et al. 2005), National Health and Nutrition Examination Survey (NHANES) (Fig. 3) (Agrawal et al. 2008), Blue Mountains Study (Gopinath et al. 2009), and National Institute for Longevity Sciences-Longitudinal Study of Aging (NILSLSA) in Japan (Uchida et al. 2012). Because varying definitions of hearing loss and different testing methodologies were used, it is difficult to compare results across the studies.

In 2012, the WHO released global estimates for hearing loss in older adults ( $>65$ years old) based on 42 population-based studies (see who. int/pbd/deafness/WHO_GE_HL.pdf).TheWHO defines disabling hearing loss as thresholds $>40 \mathrm{~dB}$ in the better hearing ear in adults (and $>30 \mathrm{~dB}$ in the better hearing ear in chil- 
The Epidemiology of Deafness

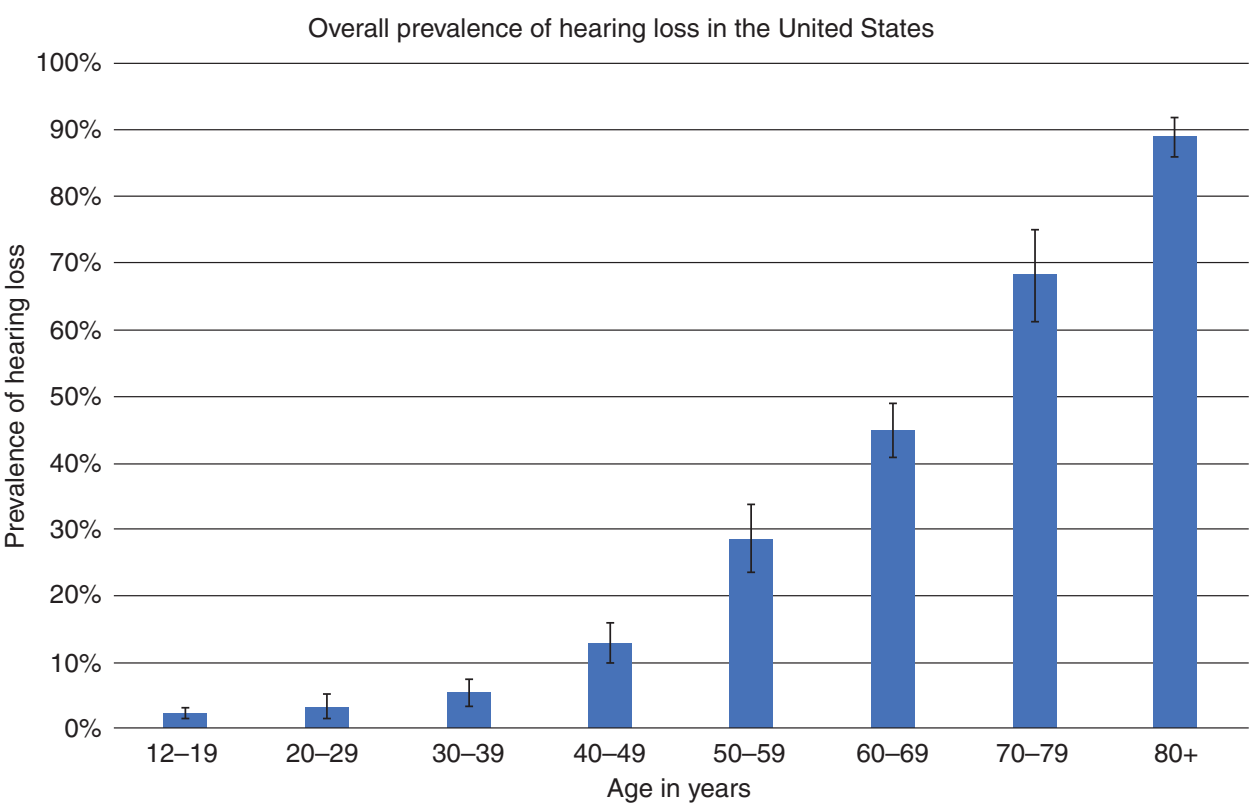

Figure 3. Prevalence of individuals in the United States with hearing loss by age. Data based on National Health and Nutritional Examination Surveys 2001 through 2008 (see Lin et al. 2011). Hearing loss is defined as thresholds of $25 \mathrm{~dB}$ or greater in at least one ear. Error bars represent 95\% confidence interval.

dren). They estimated that 164.5 million people worldwide over the age of 65 have disabling hearing loss, which represents a $33 \%$ rate of disabling hearing loss worldwide in adults older than 65 years. They also found that the prevalence of presbycusis is unequally distributed across the world, with the highest rates in subSaharan Africa, Asia Pacific, and South Asia.

In general, regions with lower average income and literacy levels tend to have higher prevalence rates of disabling hearing loss in older adults (see who.int/pbd/deafness/WHO_ GE_HL.pdf), which is an important public health concern (Roth et al. 2011). Multiple epidemiological studies have shown an association between hearing loss and dementia in older adults. A causal link between the two has not been established, but several explanations have been proposed for how hearing loss may contribute to dementia. For example, it is possible that persons with hearing loss use more cognitive resources to communicate and so are unable to expend appropriate resources for other processes. Hearing loss also leads to social isolation, which may contribute to dementia. Both disease processes could share a common etiology (e.g., small vessel disease), with hearing loss being an early manifestation of the pathology that causes dementia (Thomson et al. 2017). Thomson et al. (2017) reviewed epidemiological studies of dementia and hearing loss, and although there was variability in how the studies measured dementia, cognitive ability, and hearing loss, these studies found hearing loss to be associated with cognitive decline or with dementia. Further studies will be needed to clarify this association and the effect of various interventions.

In the United States, the NHANES has conducted hearing tests in nationally representative samples at specific ages. Data were collected from 1999 to 2004 and then again from 2011 to 2012 for adults aged 20 to 69 years old (Hoffman et al. 2017), and are generalizable to the entire civilian, noninstitutionalized population in the United States (Yamasoba et al. 2013). Hearing tests were conducted at frequencies of $0.5,1,2,3,4,6$, and $8 \mathrm{kHz}$, with speech-frequency hearing impairment defined by average thresholds of $>25 \mathrm{~dB}$ at the 0.5 to $4 \mathrm{kHz}$ frequencies; high-frequency hearing impairment 
was defined as average thresholds of $>25 \mathrm{~dB}$ at the 3 - to $6-\mathrm{kHz}$ frequencies. The most recent NHANES data (2011-2012) show that hearing loss prevalence has a strong correlation with increasing age, with overall prevalence (includes unilateral and bilateral) of speech-frequency hearing impairment increasing from $7.8 \%$ in ages $40-49$ years to $23.1 \%$ in ages $50-59$ years to $39.3 \%$ in ages $60-69$ years. High-frequency hearing impairment is even more common with an overall prevalence of $50.2 \%$ in ages $50-59$ years and $68.0 \%$ in ages $60-69$ years. In addition to age, other risk factors associated with bilateral speech-frequency hearing loss were lower educational level, male sex, and non-Hispanic white (ethnicity) (Hoffman et al. 2017).

The NILS-LSA used the same hearing loss definition as NHANES to estimate hearing loss prevalence in Japan (Yamasoba et al. 2013). The NILS-LSA sixth survey (2008-2010) data showed that prevalence of hearing loss greatly increased after the age of 65 years. The prevalence for men was $43.7 \%$ for ages $65-69,51.1 \%$ for ages $70-74,71.4 \%$ for ages $75-79$, and $84.3 \%$ for those over 80 years. Similar to the NHANES study, presbycusis was more common in males than females. The prevalence for females in the same age ranges was $27.7 \%, 41.8 \%, 67.3 \%$, and $73.3 \%$, respectively (Uchida et al. 2012). The study also noted that there were a number of elderly people who retained very good hearing, underscoring the complex etiology of presbycusis, likely involving the interplay of multiple genetic and environmental factors.

A systematic literature review published in 2011 sought to average and interpolate data from multiple studies from nations across Europe in an attempt to estimate the prevalence of presbycusis on the European continent. Although epidemiological data from the various European countries were difficult to compare because of differences in the definition of hearing loss and differences in the measurements of hearing loss, the combined data showed that $\sim 20 \%$ of women and $30 \%$ of men in Europe have hearing thresholds of $>30 \mathrm{~dB}$ at 70 years of age; by 80 years of age, these percentages increase to $45 \%$ of women and 55\% of men (Roth et al. 2011). The authors of this study conclude that presbycusis is a major health concern in Europe. They also note the need for standardized procedures for collecting, reporting, and interpreting epidemiological data on hearing loss, and recommend using the WHO classification of hearing loss for all future studies (Roth et al. 2011).

\section{Otosclerosis}

Otosclerosis is a common form of CHL that involves abnormal bony remodeling just anterior to the stapediovestibular joint of the otic capsule. This area is called the fissula ante fenestram (Nager 1969). The bony remodeling eventually leads to fixation of the stapes, which results in CHL. Disease progression to involve the cochlea can result in a sensorineural or mixed hearing loss called cochlear otosclerosis. The pathogenesis of the disease is poorly understood and both environmental and genetic factors have been implicated in the etiology.

Epidemiologic studies distinguish between histologic otosclerosis, in which otosclerotic lesions are identified in postmortem temporal bone analyses, and clinical otosclerosis, in which there is a measurable hearing loss. Histologic otosclerosis is found in up to $12.5 \%$ of the Caucasian population (Declau et al. 2007). Clinical otosclerosis is about $1 / 40$ th as common in the Caucasian population but is very rare in Asian and Black populations (Altmann et al. 1967; Tato 1967). Age-of-onset ranges from the late teenage years to the sixth decade, with average onset occurring during the third decade of life. Bilateral disease occurs in $70 \%-80 \%$ of people, and there is a 2:1 female-to-male ratio, sometimes with onset or worsening of symptoms during pregnancies. Approximately $10 \%$ of persons with clinical otosclerosis progress to cochlear otosclerosis (Ealy and Smith 2010).

Otosclerosis is considered a complex genetic disease, caused by both genetic and environmental factors (Schrauwen and Van Camp 2010). Various genetic pathways, including those involved in bone remodeling and the immune response, have been associated with increased susceptibility for otosclerosis; however, the contribution of each genetic variant is likely small. The inheritance pattern is generally con- 
sidered to be autosomal dominant with reduced penetrance, with $40 \%-50 \%$ of cases appearing to be sporadic (Ealy and Smith 2010). A variety of environmental factors are associated with otosclerosis including persistent measles virus infection and estrogen exposure (e.g., oral contraceptives). Sodium fluoride exposure (through fluoridated water) is associated with a protective effect against otosclerosis. These associations lack sufficient evidence to claim causality. One epidemiologic study in Germany reported a significant decline in otosclerosis cases among the portion of the population who received the measles vaccination (Arnold et al. 2007); however, this finding cannot explain the relatively high rates of otosclerosis in developed countries compared with its low rate in many developing countries where measles is highly endemic (Schrauwen and Van Camp 2010). As a complex disease, otosclerosis likely has many genetic and environmental contributing factors.

\section{ENVIRONMENTAL HEARING LOSS OVERVIEW}

We will conclude with an overview of environmental causes for hearing loss. It should be noted that some studies suggest that $\mathrm{CHL}$, commonly a result of treatable factors such as otitis media and cerumen impaction, is the most common cause of hearing loss worldwide (Mann et al. 1998; Tucci et al. 2010). We will focus our discussion on environmental causes of SNHL and consider two broad categories-infectious and noise-induced SNHL. Head trauma, another category of environmental hearing loss, will not be addressed but may cause both conductive and SNHL.

\section{Infectious Etiology}

Infectious causes of hearing loss can occur before or after birth. TORCH is a common acronym for organisms that may cause congenital hearing loss through prenatal exposure: toxoplasmosis, other (e.g., syphilis), rubella, cytomegalovirus (CMV), and herpes virus (Kenna 2015). Infectious etiologies for hearing loss play a significant part in the disparity between congenital hearing loss rates in developed countries compared with congenital hearing loss rates in developing countries. Universal newborn hearing screening programs in developed countries, such as the United States and European nations, report permanent bilateral hearing loss in one to two per 1000 newborns. In developing countries, without universal newborn hearing screening programs, prevalence estimates for permanent bilateral hearing loss range from 19 per 1000 newborns in sub-Saharan Africa to 24 per 1000 newborns in South Asia (Korver et al. 2017).

Congenital CMV (cCMV) infection is the most common nongenetic cause of SNHL in the world. It is the cause of hearing loss in $10 \%-20 \%$ of all children with SNHL. The rate of cCMV infection in developed countries is $0.58 \%$, with rates increasing to between $1 \%$ and $6 \%$ in developing countries with highly seropositive populations (Goderis et al. 2014). There is a $\sim 40 \%$ risk of transmission to the baby following primary infection during pregnancy, with the risk of transmission increasing with each trimester: $25 \%$ in the first trimester, $50 \%$ in the second trimester, and $75 \%$ in the third trimester. If the mother is already seropositive, the risk of vertical transmission during a reactivation or reinfection is $\sim 2 \%$ (Kenna 2015). A systematic literature review concluded that one in three symptomatic children and one in 10 asymptomatic children with cCMV will have hearing loss (Goderis et al. 2014). Symptomatic children tend to have bilateral loss, while asymptomatic children with cCMV tend to have unilateral loss. Delayed onset hearing loss may occur in children with cCMV infection (Lanzieri et al. 2017).

Congenital rubella virus infection is another important infectious cause of congenital hearing loss. Before the introduction of the rubella vaccine, it was the most common viral cause of congenital SNHL (Kenna 2015), and in countries without a rubella vaccination program, it continues to rank first (Banatvala and Brown 2004). For example, it has been reported that hearing loss secondary to congenital rubella is responsible for $30 \%-40 \%$ of the hearing-impaired population in India, highlighting the im- 
A.M. Sheffield and R.J.H. Smith

portance of vaccinations and public health initiatives as key components in the prevention of hearing loss (Tucci et al. 2010).

\section{Noise-Induced Hearing Loss}

Exposure to loud noise, particularly cumulative noise over time, is a known cause of SNHL. The first audiometric sign of noise-induced hearing loss is a threshold shift or notch at 3, 4, or $6 \mathrm{kHz}$. Threshold shifts can be temporary or permanent depending on the intensity or duration of noise exposure. Acute exposure to very loud noises (e.g., explosion) can produce immediate and permanent hearing loss. The majority of noise-induced hearing loss, however, is a result of chronic exposure to less intense noises over many years that occurs through recreational and/or work-related activities (Niskar et al. 2001).

Noise exposure is the most common modifiable cause of hearing loss in young and middleaged adults (Carroll et al. 2017). The WHO, in their 2017 update on deafness and hearing loss, estimated that 1.1 billion young people (aged 12-35) are at risk of hearing loss caused by exposure to noise in recreational settings (see who.int/news-room/fact-sheets/detail/deafnessand-hearing-loss). Occupational noise-induced hearing loss is one of the most common occupational diseases in the world (Lie et al. 2017). Twenty-four percent of hearing loss in the United States has been attributed to workplace exposure (Tak and Calvert 2008). A recent study by the Centers for Disease Control and Prevention (CDC) used NHANES data in the United States from 2011 to 2012 to evaluate for highfrequency audiometric notches in adults aged 20-69 (Carroll et al. 2017). The study found that a total of $24.4 \%$ of adults had an audiometric notch (6.2\% bilateral; $18.2 \%$ unilateral). $19.2 \%$ of adults aged $20-29$ years had an audiometric notch. The prevalence of notches was more common among males than females. Adults who reported loud noise exposure at work were twice as likely to have notches as people who did not report loud noise exposure.

Nelson and colleagues studied international occupational exposure to noise. They estimated that $16 \%$ of disabling hearing loss in adults worldwide is attributable to occupational noise exposure. The effects of occupational noise exposure were greater for males than females and higher in developing regions compared with developed regions. The highest rate was $21 \%$ in the developing Western Pacific region; the lowest rate was $7 \%$ in the developed Western Pacific region (Nelson et al. 2005).

Recreational noise exposure may be a problem as well, particularly among teenagers and young adults. NHANES data from 1988 to 1994 was used to estimate noise-induced hearing loss among school-aged children from 6 to 19 years of age (Niskar et al. 2001). The study used tympanometric compliance testing to rule out middle ear-related causes of hearing loss. The overall prevalence of a noise-induced threshold shift was $12.5 \%$. The rate was $15.5 \%$ in ages $12-19$ years compared with $8.5 \%$ in 6 - to 11-year-old children. Threshold shift was more common in males than females. The majority of cases were unilateral.

The prevalence of recreational exposure to loud music through headphones has increased significantly since the above study was performed. NHANES data from 2005 to 2006 showed $34.8 \%$ of youth aged $12-19$ years old reported exposure to loud noise or listening to music through headphones in the past 24 hours. This compared with $19.8 \%$ in the 1988-1994 survey. Nearly one-fourth of youths were exposed to steady loud noise or music for at least 5 hours per week (Henderson et al. 2011). Despite the increased prevalence of noise exposure there was, overall, no significant increase in prevalence of noise-induced threshold shifts between these time periods. The exception was with female youths, in particular, who were noted to have an increase in prevalence of threshold shifts from $11.6 \%$ to $16.7 \%$ between the two surveys. This increase eliminated the significant gender difference previously seen in threshold shifts between male and female youths. Although the reasons for this change are not entirely clear, the investigators suggest one explanation is that females are now participating in similarly loud recreational activities as males (Henderson et al. 2011). 
The Epidemiology of Deafness

It should be noted that relying solely on auditory thresholds for identification of hearing loss fails to detect hidden hearing loss (HHL). HHL is a recently described auditory neuropathy believed to contribute to speech discrimination and intelligibility deficits in people who have normal audiological tests. Moderate noise exposure and aging can result in HHL owing to defective cochlear transmission that is thought to be related to synaptopathies (Wan and Corfas 2017; Corfas 2018).

Despite the increased prevalence of reported recreational noise exposure, there is encouraging data from the most recent NHANES survey (2011-2012). This survey showed an overall decrease in the prevalence of hearing loss (unilateral or bilateral) in the United States from 15.9\% (1999-2004) to $14.1 \%$ (2011-2012) (Hoffman et al. 2017). This difference is small but significant. Explanations for this trend are merely speculation at this point, but could include increased use of hearing protection, fewer occupational noise exposures, decreased smoking, and improved diet.

\section{CONCLUDING REMARKS}

Hearing loss is a major worldwide public health concern and in 2015 ranked as the fourth leading cause of years lived with disability (Wilson et al. 2017). It affects approximately one-third of people over 65 years old and is disabling in 5\% of the world population (see who.int/newsroom/fact-sheets/detail/deafness-and-hearingloss). Approximately two-thirds of people with hearing loss live in developing countries.

As a heterogeneous disease with multiple etiologies, the cause of hearing loss spans the spectrum of genetic and environmental factors. Importantly, it is estimated that up to $60 \%$ of hearing loss is attributed to preventable causes (see who.int/news-room/fact-sheets/ detail/deafness-and-hearing-loss). Some studies, for example, suggest that CHL caused by treatable factors such as otitis media and cerumen impactions is the most common cause of hearing loss worldwide (Mann et al. 1998; Tucci et al. 2010). A significant portion of SNHL in developing countries is likely preventable as well, including SNHL caused by consanguinity, infections, and environmental exposure to ototoxic medications and loud noises (Tucci et al. 2010).

The significant disparity in the prevalence of hearing loss between developed and developing countries underscores the opportunity to intervene. Significant improvements can be made by addressing environmental causes, such as improving vaccination programs and access to diagnosis and treatment of infectious disease, improved work conditions to avoid damaging noise exposure, and improved public education regarding recreational noise exposure. Universal newborn hearing screening programs are important to identify at-risk infants to direct appropriate diagnosis and early intervention (Barsky-Firkser and Sun 1997). Increased access to nonsurgical and surgical habilitation devices such as hearing aids and cochlear implants can assist those with otherwise disabling hearing loss. Genetic diagnosis of hearing loss has grown exponentially over the past two decades and, with continued research, novel therapeutic options will become available to help those with hearing loss.

\section{ACKNOWLEDGMENTS}

This work was supported by the National Institute on Deafness and Other Communication Disorders (NIDCD) RO1s DC003544, DC002842, and DC012049 to R.J.H.S.

\section{REFERENCES}

${ }^{*}$ Reference is also in this collection.

Agrawal Y, Platz EA, Niparko JK. 2008. Prevalence of hearing loss and differences by demographic characteristics among US adults: Data from the National Health and Nutrition Examination Survey, 1999-2004. Arch Intern Med 168: 1522-1530.

Altmann F, Glasgold A, Macduff JP. 1967. The incidence of otosclerosis as related to race and sex. Ann Otol Rhinol Laryngol 76: 377-392.

Arnold W, Busch R, Arnold A, Ritscher B, Neiss A, Niedermeyer HP. 2007. The influence of measles vaccination on the incidence of otosclerosis in Germany. Eur Arch Otorhinolaryngol 264: 741-748.

Banatvala JE, Brown DW. 2004. Rubella. Lancet 363: 11271137. 
A.M. Sheffield and R.J.H. Smith

Barsky-Firkser L, Sun S. 1997. Universal newborn hearing screenings: A three-year experience. Pediatrics 99: E4.

* Bowl MR, Dawson SJ. 2018. Age-related hearing loss. Cold Spring Harb Perspect Med doi: 10.1101/cshperspect. a033217.

Brant LJ, Fozard JL. 1990. Age changes in pure-tone hearing thresholds in a longitudinal study of normal human aging. J Acoust Soc Am 88: 813-820.

Carroll YI, Eichwald J, Scinicariello F, Hoffman HJ, Deitchman S, Radke MS, Themann CL, Breysse P. 2017. Vital signs: Noise-induced hearing loss among adults-United States 2011-2012. MMWR Morb Mortal Wkly Rep 66: 139-144.

Chang KW. 2015. Genetics of hearing loss-Nonsyndromic. Otolaryngol Clin North Am 48: 1063-1072.

* Corfas G. 2018. Cochlear synaptopathy and noise-induced hearing loss. Cold Spring Harb Perspect Med doi: 10.1101/ cshperspect.a035493.

Cruickshanks KJ, Wiley TL, Tweed TS, Klein BE, Klein R, Mares-Perlman JA, Nondahl DM. 1998. Prevalence of hearing loss in older adults in Beaver Dam, Wisconsin. The Epidemiology of Hearing Loss study. Am J Epidemiol 148: $879-886$

Declau F, van Spaendonck M, Timmermans JP, Michaels L, Liang J, Qiu JP, van de Heyning P. 2007. Prevalence of histologic otosclerosis: An unbiased temporal bone study in Caucasians. Adv Otorhinolaryngol 65: 6-16.

Ealy M, Smith RJ. 2010. The genetics of otosclerosis. Hear Res 266: 70-74.

Ealy M, Lynch KA, Meyer NC, Smith RJ. 2011. The prevalence of mitochondrial mutations associated with aminoglycoside-induced sensorineural hearing loss in an NICU population. Laryngoscope 121: 1184-1186.

Gates GA, Cooper JC, Kannel WB, Miller NJ. 1990. Hearing in the elderly: The Framingham cohort, 1983-1985. Part I: Basic audiometric test results. Ear Hear 11: 247-256.

Goderis J, De Leenheer E, Smets K, Van Hoecke H, Keymeulen A, Dhooge I. 2014. Hearing loss and congenital CMV infection: A systematic review. Pediatrics 134: 972982.

Gopinath B, Rochtchina E, Wang JJ, Schneider J, Leeder SR, Mitchell P. 2009. Prevalence of age-related hearing loss in older adults: Blue Mountains Study. Arch Intern Med 169: 415-416.

Grohskopf LA, Huskins WC, Sinkowitz-Cochran RL, Levine GL, Goldmann DA, Jarvis WR, Network PP. 2005. Use of antimicrobial agents in United States neonatal and pediatric intensive care patients. Pediatr Infect Dis J 24: 766773.

Guilford P, Ben Arab S, Blanchard S, Levilliers J, Weissenbach J, Belkahia A, Petit C. 1994. A non-syndrome form of neurosensory, recessive deafness maps to the pericentromeric region of chromosome 13q. Nat Genet 6: 24-28.

Guillausseau PJ, Massin P, Dubois-LaForgue D, Timsit J, Virally M, Gin H, Bertin E, Blickle JF, Bouhanick B, Cahen J, et al. 2001. Maternally inherited diabetes and deafness: A multicenter study. Ann Intern Med 134: 721-728.

Helzner EP, Cauley JA, Pratt SR, Wisniewski SR, Zmuda JM, Talbott EO, de Rekeneire N, Harris TB, Rubin SM, Simonsick EM, et al. 2005. Race and sex differences in age- related hearing loss: The Health, Aging and Body Composition Study. J Am Geriatr Soc 53: 2119-2127.

Henderson E, Testa MA, Hartnick C. 2011. Prevalence of noise-induced hearing-threshold shifts and hearing loss among US youths. Pediatrics 127: e39-e46.

Hoffman HJ, Dobie RA, Losonczy KG, Themann CL, Flamme GA. 2017. Declining prevalence of hearing loss in US adults aged 20 to 69 Years. JAMA Otolaryngol Head Neck Surg 143: 274-285.

Kelsell DP, Dunlop J, Stevens HP, Lench NJ, Liang JN, Parry G, Mueller RF, Leigh IM. 1997. Connexin 26 mutations in hereditary non-syndromic sensorineural deafness. Nature 387: 80-83.

Kenna MA. 2015. Acquired hearing loss in children. Otolaryngol Clin North Am 48: 933-953.

Koffler T, Ushakov K, Avraham KB. 2015. Genetics of hearing loss: Syndromic. Otolaryngol Clin North Am 48: 1041-1061.

Korver AM, Smith RJ, Van Camp G, Schleiss MR, BitnerGlindzicz MA, Lustig LR, Usami SI, Boudewyns AN 2017. Congenital hearing loss. Nat Rev Dis Primers 3: 16094.

Lanzieri TM, Chung W, Flores M, Blum P, Caviness AC, Bialek SR, Grosse SD, Miller JA, Demmler-Harrison G., Group CCLS. 2017. Hearing loss in children with asymptomatic congenital cytomegalovirus infection. Pediatrics 139: e20162610.

Lie A, Engdahl B, Hoffman HJ, Li CM, Tambs K. 2017. Occupational noise exposure, hearing loss, and notched audiograms in the HUNT Nord-Trøndelag hearing loss study, 1996-1998. Laryngoscope 127: 1442-1450.

Lin FR, Niparko JK, Ferrucci L. 2011. Hearing loss prevalence in the United States. Arch Intern Med 171: 18511852.

* Mammano F. 2018. Inner ear connexin channels: Roles in development and maintenance of cochlear function. Cold Spring Harb Perspect Med doi: 10.1101/cshperspect. a033233.

Mann SB, Sharma SC, Gupta AK, Nagarkar AN, Dharamvir. 1998. Incidence of hearing impairment among rural and urban school going children: A survey. Indian J Pediatr 65: $141-145$

Nager GT. 1969. Histopathology of otosclerosis. Arch Otolaryngol 89: 341-363.

Nelson DI, Nelson RY, Concha-Barrientos M, Fingerhut M. 2005. The global burden of occupational noise-induced hearing loss. Am J Ind Med 48: 446-458.

Niskar AS, Kieszak SM, Holmes AE, Esteban E, Rubin C Brody DJ. 2001. Estimated prevalence of noise-induced hearing threshold shifts among children 6 to 19 years of age: The Third National Health and Nutrition Examination Survey, 1988-1994, United States. Pediatrics 108: 4043.

O'Sullivan ME, Perez A, Lin R, Sajjadi A, Ricci AJ, Cheng AG. 2017. Towards the prevention of aminoglycosiderelated hearing loss. Front Cell Neurosci 11: 325.

Roth TN, Hanebuth D, Probst R. 2011. Prevalence of agerelated hearing loss in Europe: A review. Eur Arch Otorhinolaryngol 268: 1101-1107. 
Schrauwen I, Van Camp G. 2010. The etiology of otosclerosis: A combination of genes and environment. Laryngoscope 120: 1195-1202.

Shibata SB, Shearer AE, Smith RJH. 2015. Genetic sensorineural hearing loss. In Cummings otolaryngology head and neck surgery (ed. Flint PW, et al.), pp. 2285-2300. Elsevier, Philadelphia.

Sloan-Heggen CM, Bierer AO, Shearer AE, Kolbe DL, Nishimura CJ, Frees KL, Ephraim SS, Shibata SB, Booth KT, Campbell CA, et al. 2016. Comprehensive genetic testing in the clinical evaluation of 1119 patients with hearing loss. Hum Genet 135: 441-450.

Smith RJ, Bale JF, White KR. 2005. Sensorineural hearing loss in children. Lancet 365: 879-890.

Tak S, Calvert GM. 2008. Hearing difficulty attributable to employment by industry and occupation: An analysis of the National Health Interview Survey-United States, 1997 to 2003. J Occup Environ Med 50: 46-56.

Tato JM. 1967. Otosclerosis and races. Ann Otol Rhinol Laryngol 76: 1018-1025.

Thomson RS, Auduong P, Miller AT, Gurgel RK. 2017. Hearing loss as a risk factor for dementia: A systematic review. Laryngoscope Investig Otolaryngol 2: 69-79.
Tucci D, Merson MH, Wilson BS. 2010. A summary of the literature on global hearing impairment: Current status and priorities for action. Otol Neurotol 31: 31-41.

Uchida Y, Sugiura S, Nakashima T, Ando F, Shimokata H. 2012. Estimates of the size of the hearing-impaired elderly population in Japan and 10-year incidence of hearing loss by age, based on data from the National Institute for Longevity Sciences-Longitudinal Study of Aging (NILS-LSA). Nihon Ronen Igakkai Zasshi 49: 222-227.

Usami S, Abe S, Shinkawa H, Kimberling WJ. 1998. Sensorineural hearing loss caused by mitochondrial DNA mutations: Special reference to the A1555G mutation. J Commun Disord 31: 423-434; quiz 434-425.

Wan G, Corfas G. 2017. Transient auditory nerve demyelination as a new mechanism for hidden hearing loss. Nat Commun 8: 14487.

Wilson BS, Tucci DL, Merson MH, O'Donoghue GM. 2017. Global hearing health care: New findings and perspectives. Lancet 390: 2503-2515.

Yamasoba T, Lin FR, Someya S, Kashio A, Sakamoto T, Kondo K. 2013. Current concepts in age-related hearing loss: Epidemiology and mechanistic pathways. Hear Res 303: $30-38$. 


\section{$\&_{\mathrm{CSH}}^{\infty} \&$ Cold Spring Harbor

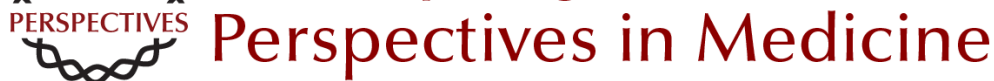

\section{The Epidemiology of Deafness}

Abraham M. Sheffield and Richard J.H. Smith

Cold Spring Harb Perspect Med 2019; doi: 10.1101/cshperspect.a033258 originally published online September 24, 2018

\section{Subject Collection Function and Dysfunction of the Cochlea}

Hidden Hearing Loss: A Disorder with Multiple Etiologies and Mechanisms

David C. Kohrman, Guoqiang Wan, Luis Cassinotti, et al.

Hair Cell Afferent Synapses: Function and Dysfunction

Stuart L. Johnson, Saaid Safieddine, Mirna Mustapha, et al.

Active Biomechanics of Sensory Hair Bundles Dolores Bozovic

The Tectorial Membrane: Mechanical Properties and Functions Jonathan B. Sellon, Roozbeh Ghaffari and Dennis M. Freeman

The Epidemiology of Deafness Abraham M. Sheffield and Richard J.H. Smith

Toward the Optical Cochlear Implant Tobias Dombrowski, Vladan Rankovic and Tobias Moser

Outer Hair Cells and Electromotility Jonathan Ashmore

Interactions between Macrophages and the Sensory Cells of the Inner Ear Mark E. Warchol
Development and Patterning of the Cochlea: From Convergent Extension to Planar Polarity Mireille Montcouquiol and Matthew W. Kelley

Hair-Bundle Links: Genetics as the Gateway to Function

Guy P. Richardson and Christine Petit

Aminoglycoside- and Cisplatin-Induced

Ototoxicity: Mechanisms and Otoprotective

Strategies

Corné J. Kros and Peter S. Steyger

Function and Dysfunction of TMC Channels in Inner Ear Hair Cells

David P. Corey, Nurunisa Akyuz and Jeffrey R. Holt

Cochlear Gene Therapy

Lawrence Lustig and Omar Akil

Age-Related Hearing Loss

Michael R. Bowl and Sally J. Dawson

Inner Ear Connexin Channels: Roles in Development and Maintenance of Cochlear Function

Fabio Mammano

A Functional Perspective on the Evolution of the Cochlea Christine Köppl and Geoffrey A. Manley

For additional articles in this collection, see http://perspectivesinmedicine.cshlp.org/cgi/collection/ 